\title{
A música como prática de promoção da saúde na adolescência
}

\author{
Music as a practice of health promotion in adolescence
}

La música como práctica de promoción de la salud en la adolescencia

\author{
Jeane Barros de Souza ${ }^{\mathrm{I}}$, Simone dos Santos Pereira Barbosa ${ }^{\mathrm{II}}$, Emanuelly Luize Martins ${ }^{\mathrm{III}}$, \\ Angélica Zanettini ${ }^{\mathrm{IV}}$, Ângela Urio ${ }^{\mathrm{V}}$, Tatiana Xirello ${ }^{\mathrm{VI}}$
}

\begin{abstract}
Resumo: Objetivo: compreender a percepção dos adolescentes participantes de um canto coral, acerca da utilização da música como instrumento para promover a saúde. Método: estudo do tipo descritivo, exploratório, com abordagem qualitativa, realizado com oito adolescentes, integrantes de um canto coral, em Chapecó-SC. A coleta dos dados desenvolveu-se por meio do grupo focal com um roteiro de questões norteadoras, no primeiro semestre de 2017. A análise e interpretação dos dados foram realizadas por intermédio da análise de conteúdo. Resultados: os adolescentes conceituaram saúde como ter alimentação saudável, dormir, fazer exercícios físicos e relataram benefícios da participação no canto coral como relaxamento, integração social, melhora da timidez e diminuição da ansiedade. Considerações finais: a prática da música, por meio do canto coral, é capaz de promover a saúde, trazendo benefícios físicos, emocionais e sociais, cabendo à enfermagem o desafio de desbravar o caminho da música na promoção da saúde dos adolescentes.
\end{abstract}

Descritores: Adolescente; Música; Promoção da saúde.

Abstract: Aim: to understand the perception of adolescents, who participate in a choral singing, about the use of music as a tool to promote health. Method: a descriptive, exploratory, qualitative study, carried out with eight adolescents, members of a choral singing, in Chapecó-SC. The data collection was developed through the focus group with a script of guiding questions, in the first semester of 2017. The analysis and interpretation of the data were performed through content analysis. Results: adolescents conceptualized health as having healthy eating, sleeping, exercising and reported benefits of participating in choral singing such as relaxation, social integration, decreasing shyness and decreased anxiety. Final considerations: the practice of music, through choral singing, is able to promote health, bringing physical, emotional and social benefits, and regards to nursing the challenge of exploring the path of music in the promotion of adolescent health.

Descriptors: Adolescent; Music; Health promotion

\footnotetext{
${ }^{\text {I }}$ Enfermeira, Doutora, Docente do Curso de Graduação em Enfermagem da Universidade Federal da Fronteira Sul- UFFS, campus Chapecó-SC, Brasil. E-mail: jeanebarros18@gmail.com. Orcid: http://orcid/ 0000-0002-0512-9765

${ }^{\text {II }}$ Discente da 7 ${ }^{\mathbf{a}}$ fase do curso de graduação em Enfermagem da Universidade Federal da Fronteira Sul- UFFS, campus Chapecó- SC, Brasil. Email: mone.96@hotmail.com Orcid: https://orcid.org/0000-0003-2328-4993

III Discente da 9ª fase do curso de graduação em Enfermagem da Universidade Federal da Fronteira Sul- UFFS, campus Chapecó- SC, Brasil. Email: emanuelly_martins@hotmail.com. Orcid:http://orcid.org/0000-0002-3160-6115

IV Enfermeira, Especialista em Cardiologia pela Universidade de Passo Fundo - UPF, Passo Fundo-RS, Brasil. E-mail: gelyzanettini@hotmail.com. Orcid: http://orcid 0000-0003-1712-9073

v Enfermeira, Residente em Obstetrícia pela Universidade Federal da Grande Dourados, Mato Grosso do Sul .Email: ange.urio@hotmail.com. Orcid: https://orcid.org/0000-0001-5851-4168

${ }^{\text {VI }}$ Discente da 9ª fase do curso de graduação em Enfermagem da Universidade Federal da Fronteira Sul- UFFS, campus Chapecó- SC, Brasil. Email: taty-xirello@hotmail.com. Orcid: https://orcid.org/0000-0002-7090-3147
} 
Resumen: Objetivo: comprender la percepción de los adolescentes, participantes de un coro, sobre de la utilización de la música como instrumento para promover la salud. Método: estudio descriptivo, exploratorio, de perspectiva cualitativa, realizado con ocho adolescentes, integrantes de un coro, en Chapecó-SC. La recolección de los datos se desarrolló por medio de grupo focal, en cual ser basó en un guion de cuestiones orientadoras, en el primer semestre de 2017. El análisis e interpretación de los datos se realizó por análisis de contenido. Resultados: los adolescentes conceptuaron salud como tener alimentación sana, dormir, hacer ejercicios físicos y relataron beneficios de la participación en el coro, como relajación, integración social, mejora de la timidez y disminución de la ansiedad. Consideraciones finales: la práctica de la música, por medio del coro, es una forma de promover la salud, proporcionando beneficios físicos, emocionales y sociales, resultando a la enfermería el desafío de conocer el camino de la música en la promoción de la salud de los adolescentes.

Descriptores: Adolescente; Música; Promoción de la salud.

\section{Introdução}

O conceito ampliado de saúde compreende bem-estar físico, mental e social, em que o Estado tem o dever de garantir por meio de ações de promoção, proteção e recuperação da saúde da população, a fim de contribuir para a manutenção de uma vida saudável e de qualidade, reduzindo o risco de doenças e agravos. ${ }^{1-2}$

$\mathrm{Na}$ adolescência se faz necessário promover a saúde, pois é um período de vulnerabilidade, uma fase em que ocorrem mudanças com possibilidades de inúmeras influências dependendo do meio social, cultural e econômico ao qual está inserido e se desenvolvendo o adolescente. ${ }^{2} \mathrm{~A}$ adolescência é um período marcado por experiências, descobertas, sonhos, incertezas, construção da identidade, projetos e alterações tanto no corpo quanto na mente, ${ }^{3}$ e é neste meio que se busca encontrar métodos de promover a saúde, evitando assim que os adolescentes passem por situações de desamparo e problemas evitáveis, visando um desenvolvimento saudável. ${ }^{2}$

Uma das estratégias para promover a saúde é a utilização da música que vem se inserindo gradativamente no processo de cuidado de enfermagem e é utilizada com o intuito de proporcionar momentos de conforto, diminuindo a tensão, os sentimentos de dor e a ansiedade, e contribuindo também na comunicação e relacionamento das pessoas, assim como possibilita momentos de lazer e relaxamento. ${ }^{4}$

A música é uma ferramenta que pode promover a saúde, pois atua no desenvolvimento físico, intelectual e emocional dos envolvidos. ${ }^{5}$ No entanto, a música geralmente é relacionada à reabilitação e à terapia na literatura, com escassez de estudos que abordam a atuação da música na promoção da saúde. ${ }^{6}$

Além de todos esses benefícios que a música produz, a atuação da Enfermagem nesse contexto é essencial, por ser uma profissão que trabalha fortemente com as relações interpessoais, desempenhando ações tanto no nível primário quanto secundário e terciário em 
saúde. A Enfermagem é uma profissão singular na promoção da saúde entre grupos socialmente vulneráveis como no caso dos adolescentes, pois atua cooperativamente com outros profissionais da área, na busca constante por melhoria na qualidade da assistência e no embate pela consolidação dos princípios do Sistema Único de Saúde (SUS), sob a ótica da integralidade e humanização no cuidado. ${ }^{7}$

Neste sentido, ao compreender a importância da música e dos seus efeitos positivos na promoção da saúde, no início de 2014, criou-se o projeto de extensão "Promovendo a saúde da criança e do adolescente através da música”, desenvolvido por acadêmicas e uma docente do curso de Enfermagem, da Universidade Federal da Fronteira Sul (UFFS), no município de Chapecó - Santa Catarina (SC). Por meio deste projeto de extensão, surgiu o Coral Encanto, composto por alunos matriculados numa escola estadual, com o intuito de promover uma vida saudável na infância e na adolescência, diminuindo o tempo ocioso dos integrantes e promovendo momentos de aprendizado mútuo por meio do canto coral. O Coral Encanto conta com aproximadamente quarenta participantes, regido por uma enfermeira, que é a coordenadora e docente responsável pelo projeto de extensão, contando com o importante apoio das acadêmicas de enfermagem para organização da logística de ensaio, escolha do repertório, atividades lúdicas e educativas, transporte e apresentações do coral.

A partir do projeto de extensão referido, constituíram-se projetos de pesquisa, sendo este artigo o resultado de um deles, que traz como questão de pesquisa: Qual a percepção dos adolescentes participantes de um canto coral sobre a prática da música como instrumento para a promoção da saúde?

Nesta perspectiva, este estudo teve como objetivo compreender a percepção dos adolescentes participantes de um canto coral, acerca da utilização da música como instrumento para promover a saúde.

\section{Método}

Trata-se de uma pesquisa exploratória, descritiva, de abordagem qualitativa. O estudo contou com a participação de oito adolescentes integrantes do Coral Encanto, sendo quatro do sexo feminino e quatro do sexo masculino, entre 12 e 15 anos, uma vez que dos quarenta coralistas, somente quinze eram adolescentes e os demais eram crianças, abaixo de 12 anos. Dos quinze adolescentes, apenas oito encaixavam-se nos critérios de inclusão, que recorriam sobre a participação no coral há mais de seis meses, a assiduidade aos ensaios que eram realizados semanalmente no espaço escolar e a participação nas apresentações realizadas em eventos e dias festivos por convites da sociedade.

Salienta-se que os participantes do estudo residiam no município de Chapecó - SC, num contexto de vulnerabilidade social e econômico em um bairro afastado do centro da cidade, com escassas atividades de lazer e cultura para diminuir o tempo ocioso. 
Foi disponibilizado para os participantes da pesquisa um Termo de Assentimento e para seus respectivos responsáveis o TCLE, mantendo assim afirmado o sigilo das informações e o aceite da participação na pesquisa. Para preservar a identidade dos participantes do estudo, optou-se em denominá-los pelo nome de notas musicais, surgindo assim: Dó, Ré, Mi, Fá, Sol, Lá, Si e o Dó Maior.

A coleta dos dados foi realizada em um dia de ensaio do coral, reservado para a realização do Grupo Focal (GF), no primeiro semestre de 2017, no próprio ambiente escolar. O GF tem o objetivo de reunir informações detalhadas sobre um tópico específico, a partir de um grupo de participantes selecionados, que busca colher informações que possam proporcionar a compreensão de percepções, crenças, atitudes sobre um tema, produto ou serviços. ${ }^{8} \mathrm{O}$ GF difere da entrevista individual por basear-se na interação entre as pessoas para obter os dados necessários à pesquisa. ${ }^{8}$

O GF desenvolveu-se em uma sala de aula com o apoio das pesquisadoras que organizaram os adolescentes sentados num círculo, oportunizando observar a interação entre os participantes e realizar anotações quanto as suas reações e falas significativas.

Para incentivar as discussões, primeiramente foi colocado um vídeo dos próprios adolescentes cantando no coral e a partir de então, desenvolveu-se o GF com o apoio de um roteiro com questões norteadoras, envolvendo temas quanto ao significado de saúde para os adolescentes, o canto coral como instrumento para promover uma vida saudável e os benefícios experenciados após ingresso no coral, com duração de, aproximadamente, duas horas. Com a utilização do gravador, os dados foram registrados, transcritos e organizados para posterior análise. Foi realizado somente um GF, devido os participantes terem respondido de maneira satisfatória os questionamentos, ocorrendo assim o fechamento amostral por saturação dos dados, no qual as informações obtidas passaram a apresentar uma certa redundância/repetição, não sendo considerado relevante persistir ou realizar novo GF para coleta de dados.

Os dados foram organizados conforme a análise de conteúdo, que é um conjunto de técnicas de análise das comunicações, com intuito de obter, por procedimentos sistemáticos e objetivos de descrição do conteúdo das mensagens, a inferência de conhecimentos relativos às condições de produção/recepção destas mensagens. ${ }^{9}$ A primeira etapa constituiu-se da préanálise, na qual foi realizada a leitura flutuante dos dados obtidos durante o GF, construção de tabela, escolhendo documentos para a constituição dos dados para serem submetidos aos procedimentos analíticos. Na segunda etapa, realizou-se a exploração do material de análise, com a organização da codificação, envolvendo três momentos: o recorte com a escolha das unidades; a enumeração, com a escolha das regras de contagem; e a classificação, com a escolha das categorias. ${ }^{9} \mathrm{~A}$ partir de então, surgiram duas categorias: a música como promotora de saúde e os benefícios do canto coral na adolescência, que para melhor encadeamento das ideias serão apresentadas em conjunto como A importância da música para a promoção da saúde na adolescência. 
A pesquisa só iniciou após ser aprovada pelo Comitê de Ética em Pesquisa da UFFS, com parecer número 2.050.383/2017, sob o Certificado de Apresentação para Apresentação Ética: 65028417.8.0000.5564, na data de 08 de maio de 2017, seguindo os preceitos da Resolução do Conselho Nacional de Saúde n 466/12.

\section{Resultados e discussão}

\section{A importância da música para a promoção da saúde na adolescência}

Com o decorrer dos anos, o conceito de saúde passou a ser entendido de maneira diferenciada. Como marco histórico desta definição, encontra-se na Carta Magna a concepção de saúde, que abrange uma dimensão social e mental, a partir de uma perspectiva mais completa e holística, somado ao completo bem-estar, com a ideia de equilíbrio e consonância na vida. Assim, a saúde começou a ser definida como um estado completo de bem-estar físico, mental e social, e não apenas como ausência de doença. ${ }^{10}$

Há grandes limites na atenção à saúde das pessoas, com evidência nos tratamentos na atenção hospitalar, medicamentoso e com enfoque somente na doença, sem ocorrer o questionamento e análise dos determinantes que poderiam ocasionar o processo saúde-doença, sem considerar aspectos culturais, vivências e experiências dos indivíduos e a incapacidade de compreender sua saúde como parte de um processo. ${ }^{11}$

O fato é que cada indivíduo possui uma definição própria de saúde, que se estabelece por meio de suas vivências, conhecimentos e valores. Neste estudo, alguns adolescentes definiram saúde como ter alimentação saudável, realizar exercícios físicos, lazer e ter um sono adequado:

ter boa alimentação, cuidar o que você come. E não ficar comendo só besteira [...]. Fazer exercícios físicos [...]. (Dó)

saúde é ter uma alimentação regular. E quando não se tem uma boa alimentação, além da mente enfraquecer, o organismo também enfraquece.

é importante o descanso, porque a gente não pode só ficar estudando, ou trabalhando, e tem que ter um tempo de lazer [...]. (Sol)

para se ter saúde também é preciso ter momentos para se divertir [...]. (Dó maior)

É relevante a concepção de saúde do indivíduo para poder valorizar os elementos que proporcionam bem-estar, conduzindo para a promoção ou manutenção deste estado de disposição. ${ }^{12}$ Em 2006 foi criada a Política Nacional de Promoção da Saúde, com o objetivo de promover a qualidade de vida e reduzir vulnerabilidade e riscos à saúde relacionado aos seus determinantes, entre os quais citado o meio ambiente, educação, lazer, cultura e acesso a bens e serviços essenciais. ${ }^{13}$ 
Também é importante destacar que uma atenção à saúde voltada concomitante para os indivíduos e a coletividade, estimula a participação destes no seu próprio cuidado, além do desenvolvimento e aprimoramento de hábitos saudáveis e condições que favorecem a saúde individual e coletiva. ${ }^{12}$

Com isso, uma das maneiras de promover a saúde é por meio da música, que está presente em vários momentos da vida das pessoas e é conhecida também como forma de linguagem para expressar as sensações, os sentimentos e as emoções:

A música é um meio de se expressar, de canalizar tanto uma raiva, uma tristeza, qualquer emoção e isso ajuda a expandir nossa mente. (Sol)

Através da música você pode se expressar, não guardar os sentimentos só para você. (Lá)

A música desperta nos adolescentes a capacidade de desenvolver um modo de se expressar interessante e ativo, podendo auxiliar o aprendizado de uma maneira prazerosa, seja este para o corpo físico ou psíquico, além de contribuir efetivamente para formação da identidade do cidadão. ${ }^{14} \mathrm{~A}$ música tem uma capacidade de influenciar diretamente o estado emocional do ser humano, devido ao fato de conseguir desencadear reações fisiológicas, cuja extensão dependerá do conteúdo emocional retrógrado do indivíduo. ${ }^{15}$ Deste modo, a percepção musical invade muitas variáveis, atingindo áreas encefálicas, influenciando todo o corpo, o que justifica as reações emocionais e fisiológicas ocorridas. ${ }^{16}$

Outro fator relevante são os benefícios que a música fornece, conforme o seu tom e ritmo, proporcionando relaxamento, agitação ou concentração:

[...] quando tu cantas a música, relaxa mais a gente, porque você pensa na música. (Mi)

se tu escutas uma música relaxada você relaxa também, se você escutar um rock pesado você já se agita. (Fá)

A música basicamente pode ser diferenciada em dois estilos: o sedativo e o estimulante. O estilo sedativo é composto por andamentos mais lentos, harmonias simples e leves variações musicais, reproduzindo relaxamento, reduzindo a frequência cardíaca, a pressão arterial e, consequentemente, a ventilação, enquanto que o estilo estimulante produz um efeito excitante, aumentando assim o ritmo da respiração, da pressão arterial e dos batimentos cardíacos, dando sensação de alerta. ${ }^{17-18}$

Nesta perspectiva, fica evidente que a música pode aumentar a atenção, além de ser um importante meio para expressar os sentimentos e emoções, desenvolvendo no indivíduo possibilidades para promover a melhoria da sua qualidade de vida. Assim, a inclusão da música em ações de promoção da saúde é de extrema pertinência, uma vez que esta favorece o desenvolvimento integral do ser. 
Por meio da música cada indivíduo adquire um aprendizado que ela desperta em seu ser, tendo diferentes significados e visão de mundo. ${ }^{6}$ Esta visão pode-se perceber no relato de alguns participantes do estudo:

eu me sinto bem, é bom fazer o coral, aprender novas coisas. (Mi)

que nem tem a música Celebrar que é uma música que significa, para você, para comemorar a vida porque, um dia ela vai acabar, então, tem que levar a vida do jeito que você pensa e aproveitar. (Fá)

gosto de pensar na letra das músicas porque elas trazem conhecimento pra gente que canta. ( $\mathrm{Si}$ )

As músicas e suas letras podem trazer profundas reflexões não apenas para os adolescentes, mas para todas as pessoas, evidenciando a importância de ter sabedoria na escolha do repertório musical de um coral, pois a música desperta sentimentos e lembranças, ocasionando em cada indivíduo uma experiência.

Com a participação no canto coral, os adolescentes podem ter um maior conhecimento sobre os diversos estilos musicais, o que proporciona ampliação da cultura, principalmente em se tratando do Brasil, que é um país intensamente rico em sua cultura musical:

E também tem vários tipos de música, que nem rock que ele é mais pesado, tem umas músicas como o jazz, e coisa e tal, [...] e tem aqueles que eles usam para levitar. (Fá)

A música é envolvida em diversos estilos musicais, apontando a diversidade das vivências e as problemáticas da sociedade como uma maneira de expressar a cultura, estando presente de várias maneiras, em diferentes povos e em diversas épocas. ${ }^{7}$

Outro benefício evidenciado pelos adolescentes quanto à participação no coral foi o aprimoramento no desempenho escolar, como na apresentação de trabalhos, superação da timidez e comunicação:

antes eu era mais tímida, depois do coral, agora eu estou me soltando mais. (Ré) que nem tinha aquela coisa de poesia que tem aqui na escola que ninguém conseguia e depois do coral, eles já começaram se soltar mais, conseguir falar em público. (Fá)

antes, eu não queria apresentar trabalho de jeito nenhum, aí eu comecei a fazer aula numa escola de música e também no coral e eu estou me soltando mais. (Lá)

antes eu era envergonhada e não conseguia apresentar, agora, depois que comecei o coral, consigo. (Dó)

O contato com a música proporciona melhoria no aprendizado devido ao empenho das atividades cerebrais, ${ }^{19}$ tornando os indivíduos envolvidos nesse processo mais sensíveis, criativos, comunicativos, imaginativos, com memória ativa, concentração, autodisciplina, 
respeito ao próximo, mais sociáveis e afetivos. ${ }^{20}$ Ainda, no coral, surge a possibilidade de desenvolver amizades e de conhecer novas pessoas e lugares:

no coral você conhece várias pessoas e lugares [...]. (Fá)

Numa apresentação as pessoas acabam cantando junto uma música e já viram amigos, já fazem vínculo com a gente e surgem novos amigos. (Lá)

O canto coral proporciona o convívio com variadas pessoas por meio dos ensaios e das apresentações em diferentes lugares, estabelecendo vínculo entre os coralistas, o que desperta a preocupação com o outro em um trabalho em equipe, ${ }^{7}$ sendo um espaço interessante para os adolescentes construírem novas amizades e assim, ampliar seu meio social. A diminuição da ansiedade também foi relatada neste estudo:

eu sou bastante ansioso, mas quando começo a cantar no coral, daí passa a ansiedade. $(\mathrm{Mi})$

A diminuição da ansiedade é outro benefício que a participação no canto coral proporciona, auxiliando no estabelecimento de habilidade sociais, que são as desenvolturas de ação do indivíduo em seu ser para com a sociedade. ${ }^{21} \mathrm{~A}$ ansiedade, principalmente em momentos de apresentações de trabalhos escolares, pode ser entendida como insegurança do adolescente em relação a escrever a resposta que sua imagem desperta no outro, sendo que a música pode contribuir para o aumento da sua autoconfiança e diminuir os seus medos e ansiedades. ${ }^{22}$

A prática do canto coral na adolescência, também pode desenvolver a criatividade e o bom humor, ${ }^{19}$ como destacado pelos adolescentes:

quando a gente começa a participar do coral você percebe que começa a ter mais criatividade e ter mais bom humor. No dia das mães eu não conseguia fazer nada e quando comecei a fazer parte do coral, sempre invento uma poesia ou uma música. (Fá)

A partir da música, pode-se alterar o humor do indivíduo, conforme a sua descrição na letra e tem-se como produto a criatividade. ${ }^{23} \mathrm{~A}$ música proporciona benefícios como redução de sensações desconfortáveis e favorecimento das sensações positivas, o que contribui para o despertar do bom humor na comunicação e integração dos indivíduos. ${ }^{7} \mathrm{~A}$ música quando entoada, torna-se perceptível, o que transmite significado cognitivo aos sinais dos neurônios, auxiliando na produção de ideias, nas atividades de aprendizagem e no despertar da criatividade do ser. ${ }^{6}$

Nos momentos de apresentação do coral, os adolescentes apontaram também o benefício da música não somente para eles, mas inclusive para os ouvintes:

tem várias músicas no coral e as pessoas que nos assistem podem refletir que precisam ser amigo do outro, que tem que ter mais respeito, carinho, ter emoções, se expressar. (Ré) 
eu acho que faz as pessoas melhor, principalmente para as que nos assistem que fazem refletir sobre a música. (Mi)

O canto coral é um instrumento para a integração social, que desencadeia um olhar de coralista para a sociedade, observando suas diferenças como cultura, o papel de cada pessoa dentro da sociedade em que vive. ${ }^{21}$ Tal realidade pode-se observar no relato de um dos adolescentes:

no coral você convive com vários tipos de pessoas, com pobre, gente mais rica, gorda, branca, negra... as pessoas ali não se diferenciam, a gente fica tudo junto e é praticamente uma família. (Fá)

A música oferece inúmeros benefícios para aqueles que a ouvem, cantam, tocam ou dançam. A música proporciona o relaxamento, a distração, o bem-estar, recordações agradáveis e conforto, além de promover momentos de interação e lazer, possibilitando na prática do canto coral a vivência da coletividade e a importância do outro que, mesmo com o crescimento individual, preza pelo coletivo. ${ }^{22}$

Alguns motivos para participar do canto coral pode ser o fato de gostar de música, de ter a oportunidade de aprender diferentes canções, de ser algo gratuito e que ainda se recebe moletom [uniforme]:

gostar da música, porque já tinha contato com a música por causa do outro projeto da escola [...]. (Lá)

[...] comecei a gostar porque você aprende vários estilos de música e também é um coral que é de graça. Você ganha moletom, camiseta. (Fá)

O principal motivo que leva os adolescentes a prática do canto coral é o gosto pela música e por seus diversos estilos, pois assim, podem expressar suas ideias, seus sentimentos, o que lhes proporcionam conhecimento próprio e a autoconfiança. ${ }^{22}$ Também tem a questão dos uniformes que o grupo recebe e, em se tratando de um local carente de recursos sociais e econômicos, o fato de o coral ser gratuito chama a atenção e desperta o interesse dos adolescentes que, em sua maioria, não teriam condições financeiras de pagar pela participação no coral.

Outro motivo que levou os adolescentes a participarem do coral foi à falta de atividades no seu cotidiano:

eu entrei porque não tinha nada para fazer, daí, como minha mãe, não gostava que eu ficasse em casa parada, só assistindo TV e mexendo no celular, me mandou começar a fazer coral. (Dó)

A falta de atividades acarreta em um tempo ocioso para os adolescentes, facilitando o envolvimento com outras atividades e situações que implicam no seu desenvolvimento saudável. Por residirem em um bairro carente em diversos aspectos, tanto econômico, sociais e também culturais, a oportunidade de participar de outras práticas de lazer encontra-se distante para os 
adolescentes e também por haver uma insuficiência de locais que sejam adequados, seguros e ofereçam gratuitamente atividades esportivas e culturais, que são extremamente importantes na adolescência. $^{24}$

Além de tudo já relatado, vale ressaltar a importância da atuação dos profissionais da saúde, que devem trabalhar de maneira dinâmica e interativa para realizar encontros agradáveis e alegres para os adolescentes. Esse importante fator também foi citado pelos adolescentes:

E também por gostar das pessoas da equipe, das professoras [...]. (Lá)

Eu continuo vindo ao coral, porque é bem legal, tem as professoras que são bem legais. (Mi)

Deve haver entre a equipe de atuação uma boa relação, pois isso facilita e contribui para a troca de conhecimentos, aprendizagem, relações sociais futuras, assim como influenciam no comportamento aos quais os adolescentes terão naquele momento compartilhado. ${ }^{25}$ Portanto, o canto coral traz benefícios físicos, emocionais e sociais, assim cabe à Enfermagem e aos demais profissionais da saúde o desafio de ousar e desbravar o caminho da música na promoção da saúde dos adolescentes.

\section{Conclusão}

Neste estudo foi possível conhecer a visão dos adolescentes sobre o conceito de saúde, sendo que alguns a entendem como ter boa alimentação, ter descanso e condições sociais adequadas, abrangendo uma concepção mais integral que se opõe à ideia simplista de ausência de doença. Também foi possível compreender que é necessária a promoção da saúde como meio para produção de um viver saudável e com qualidade de vida no adolescer.

Observou-se que a música, em específico o canto coral, utilizado como instrumento para a promoção da saúde é capaz de propiciar inúmeros benefícios, envolvendo os aspectos biológicos, psicológicos e sociais. No entendimento biológico, os adolescentes apontaram que a música proporciona o relaxamento ou estímulo das atividades cerebrais, interferência na frequência cardíaca e na comunicação. $\mathrm{Na}$ expressão psicológica, constatou-se que o canto coral promove ao adolescente a sua identidade na sociedade, a perda da timidez acontece, auxiliando no desenvolvimento escolar e no controle da ansiedade. Na questão social, além da possibilidade de desenvolver maior integração, a participação no coral permite ao adolescente enxergar realidades diferentes, destacando a diversidade cultural existente entre as pessoas, a necessidade do respeito, o convívio com diferentes pessoas, a inclusão e a criação de vínculos de amizade.

Por meio desta pesquisa foi possível evidenciar que a Enfermagem pode percorrer caminhos pouco desbravados, como utilizar a música por intermédio do canto coral na promoção da saúde, mas isso implica no desafio de estudar, ousar fazer diferente e envolver-se 
de fato com a comunidade, no intuito de oferecer uma assistência em saúde com qualidade e com criatividade para os adolescentes. Assim, este estudo traz o incentivo para novas pesquisas envolvendo a música e a promoção da saúde, já que existem escassos estudos que abordam esta temática.

No entanto, existem limitações na utilização da música no campo da saúde, pois nem todos os profissionais da área possuem conhecimento musical. Nesta perspectiva, ao haver dificuldades em utilizar a música na prática do cuidado, seja na atenção básica, como na atenção secundária e terciária, também se torna moroso o desenvolvimento de pesquisas na área pelos profissionais da saúde por não ter proximidade com a música, acarretando na pouca produção científica. Um fator limitante para a realização desta pesquisa foi justamente a escassa produção da temática proposta, voltada para a utilização da música como promotora da saúde, evidenciando a necessidade de novos estudos.

Sugere-se o incentivo da utilização da música na assistência ao promover a saúde não apenas dos adolescentes, mas do público em geral, recomendando novos estudos sobre os benefícios da música no cuidado aos indivíduos, bem como a publicação de experiências exitosas na área. Sugere-se também que a equipe de saúde atue de forma intersetorial, buscando o apoio de músicos e musicoterapeutas para que juntos, num trabalho multiprofissional, possam desenvolver ações em prol da saúde na comunidade.

\section{Referências}

1. Brasil. Constituição (1988). Constituição da República Federativa do Brasil: texto constitucional promulgado em 5 de outubro de 1988, com as alterações determinadas pelas Emendas Constitucionais de Revisão $\mathrm{n}^{\text {os }} 1$ a 6/94, pelas Emendas Constitucionais n $\mathrm{n}^{\text {os }}$ 1/92 a 91/2016 e pelo Decreto Legislativo no 186/2008. Brasília (DF): Senado Federal, Coordenação de Edições Técnicas; 2016. [acesso em 2018 set 03]. Disponível em: https://www2.senado.leg.br/bdsf/bitstream/handle/id/518231/CF88_Livro_EC91_2016.pdf.

2. Cunha LGH, Oliveira MC. Política de saúde para adolescentes na perspectiva dos direitos humanos: reflexões a partir de um hospital de trauma [Internet]. In: XII Seminário Nacional Demandas Sociais e Políticas Públicas na Sociedade Contemporânea. 2016 [acesso em 2017 out 08]. Disponível em: https://online.unisc.br/acadnet/anais/index.php/snpp/article/download/14759/3594.

3. Sasaki RSA, Leles CR, Malta DC, Sardinha LMV, Freire MCM. Prevalência de relação sexual e fatores associados em adolescentes escolares de Goiânia, Goiás, Brasil. Ciênc Saúde Colet [Internet]. 2015 [acesso em 2018 set 03];20(1):95-104. Disponível em: http://www.scielo.br/pdf/csc/v20n1/1413-8123-csc-2001-00095.pdf.

4. Santana DST, Zanini CRO, Souza, ALL. Efeitos da música e da musicoterapia na pressão arterial: uma revisão de literatura. InCantare [Internet]. 2014 [acesso em 2017 set 22];5:37-57. Disponível em: http://periodicos.unespar.edu.br/index.php/incantare/article/view/261. 
5. Finger D, Urio A, Zanettini A, Franceschi VE, Souza JB, Haag FB. Cantando e encantando: uma experiência de promoção da saúde através da música [Internet]. In: Anais do Seminário de Ensino, Pesquisa e Extensão. 2015 5(1):1-2. Chapecó: Universidade Federal da Fronteira Sul; 2015 [acesso em 2018 jan 26]. Disponível em: https://periodicos.uffs.edu.br/index.php/SEPE-UFFS/article/viewFile/2441/1721.

6. Finger D, Zanettini A, Urio A, Franscechi VE, Souza JB, Haag FB, et al. Atuação da música no desenvolvimento saudável de crianças e adolescentes. Rev Ciênc Ext [Internet]. 2016 [acesso em 2017 set 24];12(2):106-15. Disponível em: http://ojs.unesp.br/index.php/revista_proex/article/view/1316/1236.

7. Zanettini A, Franceschi VE, Souza JB, Franceschi VE, Finger D, Haag FB, et al. Quem canta seus males espanta: um relato de experiência sobre o uso da música como ferramenta de atuação na promoção da saúde da criança. REME Rev Min Enferm [Internet]. 2015 [acesso em 2017 set 04];5(1):1-2. Disponível em:

http://www.dx.doi.org/10.5935/1415-2762.20150079.

8. Trad LAB. Grupos focais: conceitos, procedimentos e reflexões baseadas em experiências com o uso da técnica em pesquisas de saúde. Physis (Rio J) [Internet]. 2009 [acesso em 2018 Set 06];19(3):777-96. Disponível em: http://www.scielo.br/scielo.php?script=sci_arttext\&pid=S010373312009000300013\&lng=en. doi: http://dx.doi.org/10.1590/S0103-73312009000300013.

9. Bardin L. Análise de Conteúdo. São Paulo: Edições 70; 2011. 229 p.

10. Organização Mundial da Saude (OMS). La salud del adolescente y el joven en las Américas. Publicación Científica no 489. Washington: OMS; 1985.

11. Fertonani HP, Pires DEP, Biffi D, Scherer MDA. Modelo assistencial em saúde: conceitos e desafios para a atenção básica brasileira. Ciênc Saúde Colet [Internet]. 2015 [acesso em 2017 set 04];20(6):1869-78. Disponível em: http://www.redalyc.org/articulo.oa?id=63038653023.

12. Brasil. Ministério da Saúde. Secretaria de Vigilância em Saúde. Secretaria de Atenção à Saúde. Política Nacional de Promoção da Saúde. Brasília (DF): Ministério da Saúde; 2006. [acesso em 2017 set 02]. Disponível em: http://bvsms.saude.gov.br/bvs/publicacoes/politica_nacional_promocao_saude_3ed.pdf.

13. Lima GP, Sant'Anna VLL. A música na educação infantil e suas contribuições. Pedagogia em Ação [Internet]. 2015 [acesso em 2017 set 10];101-16. Disponível em: http://periodicos.pucminas.br/index.php/pedagogiacao/article/viewFile/9227/7680.

14. Moreira AC, Santos H, Coelho IS. A música na sala de aula: a música como recurso didático. Unisanta Humanitas [Internet]. 2014 [acesso em 2018 jan 23];3(1):41-61. Disponível em: http://periodicos.unisanta.br/index.php/hum/article/view/273.

15. Fiossi-Kpadonou E, Sessou DV, Kpadonou GT, Agossou T. Music and emotions of teenagers in Benin. J Child Adolesc Behav [Internet]. 2016 [acesso em 2018 set 06];4(6):1-7. Disponível em: 
https://www.omicsonline.org/open-access/music-and-emotions-of-teenagers-in-benin-2375-44941000323.pdf.

16. Weigsding JA, Barbosa CP. A influência da música no comportamento humano. Arq Mudi [Internet]. 2015 [acesso em 2017 set 12];18(2):47-62. Disponível em: http://www.periodicos.uem.br/ojs/index.php/ArqMudi/article/view/25137/pdf_59.

17. Sousa ASSCP. Música e saúde: uma arte ao serviço da Ciência Médica [Internet]. Porto (Portugal): Universidade do Porto. Instituto de Ciências Biomédicas Abel Salazar; 2013. [acesso em 2017 set 07]. Disponível em: https://repositorio-aberto.up.pt/bitstream/10216/71744/2/30598.pdf.

18. Amaral JB. A música como terapia complementar na paliação da dor em idosos hospitalizados: à luz da Teoria de Jean Watson [tese]. Salvador (BA): Universidade Federal da Bahia; 2013. 262 p. [acesso em 2018 jan 23]. Disponível em: https://repositorio.ufba.br/ri/bitstream/ri/12108/1/TESE\%20JULIANA\%20AMARAL.pdf.

19. Santos LS, Parra, CR. Música e neurociências inter-relação entre música, emoção, cognição e aprendizagem. Psicologia.pt: o portal dos psicólogos [Internet]. 2015 [acesso em 2018 jan 23];1-8. Disponível em: http://www.psicologia.pt/artigos/textos/A0853.pdf.

20. Carminatti JS, Drug JS. A prática de canto coral e o desenvolvimento de habilidades sociais. Pensamiento Psicológico [Internet]. 2010 [acesso em 2018 set 03];7(14):81-96. Disponível em: http://revistas.javerianacali.edu.co/index.php/pensamientopsicologico/article/viewFile/134/399.

21. Aráujo LL. A música da minha vida [trabalho de conclusão de curso]. Brasília (DF): Universidade Católica de Brasília; 2015. [acesso em 2017 set 04]. Disponível em: https://repositorio.ucb.br/jspui/bitstream/123456789/8790/1/LuanaLandimAra\%C3\%BAjoTCCGraduacao2 015.pdf.

22. Motta P, Schimitt V. Valores gerenciais, carreiras profissionais e inclusão social: o aprendizado de música clássica em comunidades carentes. Rev Port Bras de Gest [Internet]. 2016 [acesso em 2018 fev 23];15(2):4-23. Disponível em: http://www.redalyc.org/pdf/3885/388548518002.pdf.

23. Oliveira MF, Oselame GB, Neves EB, Oliveira EM. Musicoterapia como ferramenta terapêutica no setor da saúde: uma revisão sistemática. Rev Univ Vale Rio Verde [Internet]. 2014. [acesso em 2017 set 22];12(2):871-8. Disponível em: http://periodicos.unincor.br/index.php/revistaunincor/article/view/1739.

24. Dias DF, Loch MR, Ronque VER. Barreiras percebidas à prática de atividades físicas no lazer e fatores associados em adolescentes. Ciênc Saúde Colet [Internet]. 2015 [acesso em 2017 set 23];20(11):3339-50. Disponível em: http://www.scielo.br/scielo.php?script=sci_arttext\&pid=S141381232015001103339\&lng=en\&nrm=iso\&tlng=pt.

25. Batista AP, Weber LND. Interação professor e aluno no ensino fundamental: um panorama de estudos nacionais. Cad Pesqui Pensam Educ [Internet]. 2014 [acesso em 2017 set 23];9(23):188-208. Disponível em:https://seer.utp.br/index.php/a/article/view/533. 


\section{Autor correspondente}

Jeane Barros de Souza

E-mail: jeanebarros18@gmail.com

Endereço: Rua Guaporé, n.299 E, apto 805, Bairro Centro, Chapecó-SC.

CEP: 89802300

\section{Contribuições de Autoria}

\section{1 - Jeane Barros de Souza}

Participou da concepção e planejamento do projeto de pesquisa, coleta, organização e interpretação dos dados, redação e revisão crítica.

\section{2-Simone dos Santos Pereira Barbosa}

Participou da coleta, organização e interpretação dos dados, e da redação do artigo.

\section{3 - Emanuelly Luize Martins}

Participou da coleta, organização e interpretação dos dados, e da redação do artigo.

\section{4 - Angélica Zanettini}

Participou da coleta, organização e interpretação dos dados, e da redação do artigo.

\section{5 - Ângela Urio}

participou da coleta, organização e interpretação dos dados, e da redação do artigo.

\section{6 - Tatiana Xirello}

Participou da coleta, organização e interpretação dos dados, e da redação do artigo

\section{Como citar este artigo}

Souza JB, Barbosa SSP, Martins EL, Zanettini A, Urio A, Xirello T A música como prática de promoção da saúde na adolescência. 2019 [Acesso em: 2019 jun 15];vol(num):1-14. DOI:https://doi.org/10.5902/2179769230379 